\title{
ENHANCING REGIONAL ANALYSIS WITH THE DELPHI METHOD
}

\author{
Mark M. Miller*
}

\begin{abstract}
Delphi methodology has been employed since the 1950s in a wide range of fields and applications, typically as an alternative to quantitative modeling and analysis. Based on the author's experience in urban planning and economic development applications, this technique can also appropriately and usefully serve as a complement to quantitative regional analysis. The appropriate application of Delphi methodology in this regard can address a number of important concerns in regional planning analysis, including how to effectively incorporate a qualitative dimension into quantitative data, how to most efficiently utilize scarce data collection and analysis resources, and how to turn data into "usable knowledge" for planning decision makers. In this way, Delphi methodology may provide an effective means of bridging the gap that commonly exists between regional planning analysis and its policy applications. Two case studies are provided, illustrating the practical application of this technique in a regional science context.
\end{abstract}

\section{INTRODUCTION}

The "Delphi" methodology was developed in the 1950s as means by which a diversity of expertise could effectively be brought to bear on complex, multidimensional, or otherwise particularly difficult problems. The technique has been widely utilized since that time in a broad range of planning, public policy, and business applications. Most typically, the Delphi technique is categorized as a qualitative methodology (Patton 1990) and employed as an independent alternative to quantitative methods (Heikkila and Leckie 1989).

The purpose of this paper is to suggest several ways in which Delphi methodology can also serve as an appropriate and useful complement to, or means of enhancing, quantitative regional analysis. The appropriate application of Delphi methodology can address a number of important and longstanding concerns in regional analysis, including:

- Incorporating a qualitative dimension into quantitative data.

- Maximizing the utility of scarce data collection and analysis resources.

- Tuming data into "usable knowledge" for planners and policymakers.

\footnotetext{
*Assistant Professor, Department of Geography and Area Development, The University of Southern Mississippi, Hattiesburg.
} 
The following section of this paper provides some background on the use and applications of Delphi methodology. The third section expands upon the above list of potential applications for Delphi methodology in regional analysis. The fourth section discusses some practical considerations for applied regional scientists who may consider utilizing the Delphi method, based on the author's experience with a wide variety of Delphi-type studies. The fifth section provides two case studies in which Delphi methodologies were utilized: a metropolitan growth study and a regional economic development planning study. These case studies are intended to illustrate the above applications of the Delphi methodology in regional analysis and the practical use of the Delphi technique in regional science applications.

\section{DELPHI METHODOLOGY: SOME BACKGROUND}

"Delphi" methodology originated with the Rand Corporation in the 1950s as a technique for forecasting and problem solving involving highly complex issues (Gordon and Helmer 1964). In its most general form, the method is characterized by a panel of experts who respond to an iterative series of written questionnaires. Traditionally, the "experts" involved represent either a broad diversity of fields or a diversity of experience within a given field. The Delphi participants may be physically brought together for the purpose, or more typically questionnaires are distributed and collected by mail. (The two case studies that follow were conducted entirely by mailed correspondence.)

Each set of questionnaires and the responses returned by the panel of experts is termed a "round." Following each round, the responses to the questionnaires are analyzed by a panel moderator, and the results are summarized and reported back to the panel members. The moderator also is responsible for developing subsequent questionnaires based on these responses, with the intention of further clarifying and refining the responses with each new round (see, for example, Delbecq et al. 1975, or Gibson and Miller 1990, for additional discussion of Delphi methodology).

The principle of the Delphi methodology is that individual panelists may revise their initial opinions on an issue in light of other experts' responses, or they may benefit from learning of additional issues or dimensions of the problem that they may have overlooked in earlier responses. To the extent that this occurs, the Delphi method can provide an effective technique for encouraging progress toward consensus-or at least some degree of convergence-among the participants.

Over the years, the Delphi method has been refined (Linstone and Turoff 1975; Erffmeyer et al. 1986; Cundiff 1985), and many variations on the original 
Delphi methodology have been developed (Delbecq 1975; Murray et al. 1985; Nelms and Porter 1985). Delphi and Delphi-type methodologies have been applied to problems in a wide range of fields, including various aspects of public administration (DeSario and Langton 1987; Preble 1983; Strauss and Zeigler 1982) and public finance (Heikkila and Leckie 1989), urban analysis (Masser and Foley 1987; Ley and Anderson 1975; Ozbekhan 1978), economics and economic policy (Cicarelli 1984; Winter and Gunjal 1986), energy policy (Setty 1987), transportation and communication planning (Sviden 1988; Cavallisforza and Ortolano 1984; Pelton 1981), resource and environmental management (Bardecki 1984; Benarie 1988; Miller 1986; Side 1986), education and training (Shands and Levary 1986; Weaver 1988), higher education policy (Kruus 1983), business and marketing (Scott and Troberg 1980), and health care (Hitch 1983; Shelton 1985). The case study section of this paper describes some of the author's own applications of Delphi methodology in the fields of economic and community development planning.

A substantial body of research also appropriately concerns the validity of the Delphi methodology (Heikkila and Leckie 1989; Masser and Foley 1987; Riggs 1983; Sackman 1975). Most of the critical research concerns the methodology's validity and effectiveness as a descriptive or predictive modeling instrument, i.e., does the Delphi technique really apply expertise to a problem in a systematic, meaningful, and replicable manner? Researchers have compared, for example, the outcomes of separate Delphi expert panels working on identical problems (Heikkila and Leckie 1989) and contrasted the forecasts of a Delphi panel of experts with those of a Delphi panel comprised of less expert participants (Riggs 1983). The cumulative results of such studies have been interesting and encouraging but inconclusive to date-particularly since a satisfactory theoretical basis has not yet been established to support the use of Delphi methodology as a "standalone" forecasting technique.

\section{DELPHI METHODOLOGY AS A COMPLEMENT TO QUANTITATIVE REGIONAL ANALYSIS}

Debate in this regard, however, obscures what may constitute an even broader and more promising range of applications of Delphi methodology for planning and public policy: as a complement to, rather than a substitute for, quantitative methods of modeling and analysis. In particular, Delphi methodology can potentially provide a useful means of bridging the gap that often exists between regional analysis and its incorporation into public policy. 
The introduction of this paper identified three broad categories of applications in this regard. They are based on the author's own experience with the Delphi applications and are not intended to be an exhaustive list of such possible applications. At the least, however, Delphi methodology may be appropriately utilized by the applied regional analyst to accomplish these ends:

\section{Incorporation of a Qualitative Dimension into Quantitative Data}

It is hardly revolutionary to suggest that intangibles, or qualitative considerations, can have an enormous influence on policy and planning decisions; in many cases, these intangibles challenge and even overwhelm the relevant quantitative data (Bachelor 1991). In land use planning, for example, important qualitative considerations commonly include nuisances; aesthetic impacts; impacts on the local quality of life or sense of place; and public perceptions of noise, convenience, or safety (in some cases, contrary to quantitative measures of such factors).

Utilizing the available quantitative data, a Delphi panel can help assess the qualitative impacts of plans, projections, or policy proposals. Given a projected level of growth in a community, for example, or a projected increase in traffic through a neighborhood, how will the character of these areas be changed? Which groups within the community will benefit in terms of their quality of life, and which will be affected adversely? How will the changes affect the social or political integrity of the community?

To be certain, planning and policy researchers have grappled with these considerations since the beginning of quantitative modeling, employing hedonic pricing and various other mechanisms. Delphi methodology provides one additional technique for the analyst's toolbox, but one that may be particularly appropriate in certain cases. Depending on the circumstances, for example, a Delphi study may be more cost-effective than collecting and incorporating the necessary data into a quantitative model. Perhaps more important, as illustrated in the case studies that follow, a Delphi-based approach may be more intuitive to the policymakers or other community decision makers involved, and so more likely to be accepted and utilized.

\section{Maximization of the Utility of Scarce Data Collection and Analysis Resources}

Delphi techniques can potentially serve a number of purposes in this regard, including to enhance the "shelf life" of existing studies and databases, to target scarce data collection and analysis resources, and to provide a regional dimension to regionally aggregated data. Perhaps nothing is more frustrating to the conscien- 
tious social scientist than to have a good study simply gather dust on the shelf after completion-apparently never influencing public opinion or policy decisions. A Delphi study can be employed to "dust off," or to help retain the value of, previous studies-which may in turm reflect favorably on the usefulness of a new, proposed study.

A Delphi panel may be convened, in this regard, in either the pre-study or poststudy stage. In the former case, a panel might be employed to assess what additional data would most effectively and efficiently support planning and decision-making processes. In the poststudy case, a Delphi panel can be asked how the new data relate to previous studies. Are the results of the new study consistent with the conclusions of previous studies? If the new data appear to contradict the old, why is that so?

In many cases, policymakers will have access to a general model but will desire more disaggregated data for special situations or particular decisions. The development of a more disaggregated version of the model often will be impractical, given the availability of data or the policymaker's resource and time constraints. In a case study that follows, for example, a Delphi panel had access to an economic and population growth model for the Tucson metropolitan area. Given the importance of neighborhood politics within the metro-polis, this panel was convened largely in order to comment on the likely intrametropolitan distribution of growth. Admittedly, this last application violates this paper's own, earlier cautions against utilizing Delphi methodology as a substitute for quantitative methods. Based on the author's experience, however, a well-constituted Delphi panel can generally provide reliable and useful results in a constrained exercise such as this-at least to the degree of accuracy or validity necessary for many planning or policy decisions.

\section{Turning Data into "Usable Knowledge" for Policy and Decision Makers}

Lindblom and Cohen (1979) coined the term "usable knowledge" to denote data and information that are useful to, and utilized by, public policy and decision makers. As they suggest, "In public policy making, many suppliers and users of social research are dissatisfied, the former because they are not listened to, the latter because they do not hear much they want to listen to" (p.1). They cite empirical work in this regard by Weiss (1977) and others. Delphi methodology may serve in a number of ways to help enhance the "usefulness" of quantitative research to public policymakers.

A Delphi process can help to make the methodologies and results of quantitative research more meaningful, or comprehensible, to public policymakers or to the greater public at large. A Delphi process also can assist the policy or 
decision maker to analyze a research study critically in order to gain more confidence in the design and results of the study.

In the case of planning or policy models that generate a number of alternative scenarios, for example, a Delphi panel can be asked which is the most likely scenario and why. Through this process, participants will be called upon to understand and question the assumptions and design of a model and to make sense of the resulting output. By comparing their own understanding and interpretation of a model with that of others on the panel, participants can gain a much deeper understanding and appreciation of the model through the Delphi process than through a cursory reading of a model's outputs.

In addition to understanding a model, in a rational sense, planners, policymakers, and community decision shapers also must "buy into" a model before they can be expected to incorporate its results fully into their decision process. New studies must be added to the decision maker's existing framework of available data, previous studies, and what Lindblom and Cohen (1979) term "ordinary knowledge": experience, heresay, intuition, and biases. A study that contradicts the policymaker's prior conceptions, or that does not fit neatly or clearly into the policymaker's existing frame of reference, is likely to be discounted at best or entirely disregarded at worst. A Delphi panel for a regional planning study would typically include representatives of any regions or groups potentially affected by the plan in question, e.g., community or neighborhood representatives, environmentalists, or advocates for minority groups or the poor. In many cases, these participants would not give a great deal of consideration or credence to the forecasts of a computer model, simply having read a report on the subject. As participants in a Delphi study of this nature, however, they would be asked to evaluate the model's forecasts critically in terms of their own framework of professional and "ordinary" knowledge. Does the methodology of the study or the design of the model make intuitive sense? Are the results of the model consistent with the Delphi panelists' own knowledge and experience? When the data run counter to their own knowledge and experience, why is that the case? Is the model flawed, are they interpreting the results correctly, or does the model incorporate some factors that they had not considered to that point? A sincere social science researcher can ask for nothing better than to have his or her work evaluated this carefully and critically by policymakers and shapers.

A Delphi panel can also enhance the "usefulness" of a policy study by helping to translate raw data, forecasts, and analyses into some of the less tangible, but no less important, aspects of policymaking or planning. These may include considerations such as lines of responsibility, political exigiencies, implementation strategies, control, priorities, or financing. Delphi panelists also may be able to suggest means of mitigating the negative impacts of a plan or policy. 
Finally, the Delphi process can be a highly effective means of simply calling attention to a regional model or other research project. The participants in a Delphi study of this nature will be directly and fully exposed to the project, and these participants typically will include government representatives and other community leaders. The author's experience with Delphi research also has shown that such studies can prove very newsworthy. Such studies generally address topics that are of current interest to the community and its leadership. Delphi studies can often reveal surprising levels of agreement on particular topics. It may be of interest, also, simply to identify the degree and extent of disagreement on certain topics. Delphi studies can often serve to elicit a number of perspectives on a problem-or potential solutions to a problem-that have not been widely recognized.

\section{PRACTICAL CONSIDERATIONS IN THE APPLICATION OF THE DELPHI METHOD}

There are, of course, a number of other methodologies for eliciting "expert" opinion on regional planning or policy issues. These include more structured and formal methodologies such as focus group or nominal group (Delbecq et al. 1975) techniques. Less formally structured techniques might range from an extensive process of in-depth interviews with community opinion leaders to the assessment of a single experienced development consultant. The author's experience includes all of these methods and hybrids thereof. All of them have appropriate applications and an appropriate place in the "tool box" of a regional development analyst. Based on the author's experience, however, the Delphi technique can potentially be one of the most useful, effective, and flexible techniques of this collection. Following are a number of advantages of the Delphi method over other "expert" analysis techniques.

From the perspective of the regional scientist, probably the most important advantage of the Delphi method is its effectiveness in exposing lay participants to dense data sets, regional models, and complex outputs. The first case study presented in this paper provides an example of this. A Delphi process can allow the participants enough time to study materials at their own pace and their own convenience-particularly if the process is conducted by mail over a period of a few weeks. A Delphi survey can be designed to guide participants through fairly dense materials. As illustrated in the case study that follows, lay participants were provided with relatively complex results from an econometric model. The participants were then asked a series of questions about particular aspects of and 
results from the model, e.g., regarding the reasonableness of a particular assumption or result of the model.

Participants can also be encouraged to call or meet with the analysts in order to clarify any questions regarding such materials. This may require some sensitivity on the part of the study coordinator so that the participants are not embarrassed to admit that they do not understand something. It must be made clear to the participants that it is very likely they or anyone else (even another professional analyst) would have some questions about the materials-indeed, questions are a reflection of thoughtful and careful study.

Another very important advantage of the Delphi method is its strength as an instrument for encouraging "brainstorming," or developing a wide range of ideas and perspectives on an issue. Depending on the circumstances, this alone may be one of the most important outcomes of a Delphi study. Other techniques, such as Nominal Group, also serve this purpose. The Delphi process, though, is particularly well suited to funneling these initial brainstorms toward a more useful and focused convergence of opinion.

Pragmatically speaking, depending on the circumstances and nature of the study, the most important advantage to the Delphi method may be the broad participation that it permits and the resulting exposure and publicity for the study. Given adequate resources, there is probably no methodological or practical limit on the number of participants in a given Delphi study. In the author's experience, beyond the first 30 or so responses, additional responses generally do not contribute much new information, so there may even be economies of scale in large Delphi groups. In other techniques that require direct interaction among the participants, it is generally hard to manage more than 30 or so participants in a room.

The Delphi technique may or may not be economical compared with alternatives, depending on the circumstances of a particular study. If a study involves participants in scattered locations, for example, a Delphi process by mail is likely to be less expensive than personal interviews. A thorough Delphi process is never inexpensive, though. It almost always involves a great deal of researcher time, assistance, postage, materials, phone expense, etc.

A strength of the Delphi process is that it still, after all these years, elicits a certain curiosity factor. Most people have heard of the technique and may associate it with atomic strategy or other exotic applications. The process itself is interesting and somewhat unusual. It permits participants to interact and compare their thoughts with people they normally may not encounter but in a relatively non-threatening forum.

A final pragmatic advantage of the Delphi method is that the process generally elicits many good quotes from the participants, which make for good press and more lively reports. Participants are assured from the beginning of the 
study that all individual responses will be kept anonymous. Quotes may be used to illustrate extreme positions on some issues (e.g., references to community environmentalists as "nature nazis") or to render a consensus view more graphic and memorable. This response from a Delphi study participant, for example, was widely quoted in the local media: "Without major planning initiatives, there is a very good chance that Tucson of 1995 will be termed a disaster, in terms of population, traffic, water, etc.; there is no longer plenty of time in which to act."

\section{TWO CASE STUDIES: DELPHI APPLICATIONS IN METROPOLITAN GROWTH AND REGIONAL ECONOMIC DEVELOPMENT STUDIES}

Following are two case studies of Delphi applications to regional development problems. The first is a study of population growth and economic development in the Tucson metropolitan region. The second is an economic diversification planning study for a rural county in Arizona, which was devised as a model for other highly military-dependent communities in the United States.

\section{A Metropolitan Growth Study}

In 1985, the University of Arizona sponsored a community forum on the growth and development of the Tucson metropolis titled "Development for Tomorrow: Options and Choices." In association with this forum, the university's Division of Economic and Business Research provided a computer simulation forecast of Tucson's growth from 1985 through 2000 (Charney and Silvers 1985).

This model generated six growth scenarios, or alternative simulations. The first simulation was a control run, or the most probable forecast for the metropolis based on current trends. The model forecasted changes in population, employment, personal income, per capita manufacturing income, local revenues, and the number of local workers available for work relative to the number of new jobs (a local worker absorption measure). This control run was compared with five alternative scenarios: very rapid employment growth, very rapid employment decline, a population growth control scenario, moderately rapid employment growth, and moderately rapid growth with population growth controls.

Also, as part of this community forum, the university's planning program was commissioned to address the regional, political, environmental, and other quality-of-life aspects of growth that were not explicitly addressed in the quantitative model. One of the most important of these additional considerations was the regional character of metropolitan growth. At that time, Tucson was experiencing 
a number of issues-such as freeway and other traffic planning-that were pitting neighborhood against neighborhood. At the same time, neighborhood associations were becoming more politically and legally sophisticated, thus emerging as a major (and increasingly divisive) factor in local political decision making. The original computer simulation modeled the metropolitan area as a whole, but it was clear that the intrametropolitan dynamics of growth would be just as critical.

The researchers involved designed a community Delphi study that utilized the computer simulations of the Division of Economic and Business Research as an objective foundation (Mann and Miller 1985). This combined approach offered a number of advantages. The Delphi method provided a means of addressing the many qualitative considerations associated with the area's growth including important considerations of neighborhood-level impact. The Delphi method would also give the study wide and intensive exposure among Tucson's leaders. This served an important, implicit goal of the university in sponsoring this project: the community had been experiencing a number of "town versus gown" problems such as campus encroachment into nearby residential neighborhoods, traffic problems in the vicinity of campus, etc.

The Delphi method also offered a means of explicitly incorporating all of the many factions comprising the metropolitan community. This was critical to the practical success of the project, since growing divisiveness within the community was widely recognized as an important problem. The increasingly complex nature of development and growth in Tucson also demanded widely diverse representation.

Accordingly, the first and probably most important step of the Delphi study in this case was to identify a broadly representative panel of expert participants. A few interviews with community officials and activists resulted in the list of categories represented in Table 1.

Once these categories were established, it was not difficult to identify two or three recognized community leaders in nearly every category. As a check, the first letter to study participants solicited their recommendations of other community leaders who should be included in such a study. Approximately 70 people ultimately accepted an invitation to participate in the study, many of whom represented two or more categories of interest.

Initially, all of the participants were provided with a letter explaining the upcoming Delphi process and with copies of two documents. The first document was a previous planning report for the metropolis, the result of a joint Urban Land Institute/American Institute of Architects (ULI/AIA) commission. The second document provided the quantitative results of a few of the computer-generated growth scenarios, together with an explanation of the computer model and a ver- 
TABLE 1

Representative Panel of Expert Participants

\section{Manufacturing}

General business and services

University

Arts and culture

Recreation

Economic development

Elected government officials

Hispanic community

Clergy

Neighborhood associations

Media

Nonprofit/volunteer

Historic preservation

Utilities and other services

Tourism
Construction and development

Public education

Community college

Health

Conservation/environmental protection

Criminal justice

Appointed government officials

Other minority groups

Retirement community

Military

Farming/rural metropolitan fringe

Transportation

Planning

Major landowners

Banking

bal interpretation of the results in layperson's language. For example,

Alternative number three requires a bit more imagination. It projects that a healthy economy continues, just as in the "control." At the same time, for some reason a very strict "no-growth" policy is enacted. Under this policy, net inmigration to Tucson is stopped completely. Natural population growth continues (i.e., our children and grandchildren can stay here), but no families may move to Tucson unless a local family leaves. Granted, this is hardly likely to occur (although it's not unheard of in the U.S.), but if we can suspend our disbelief this can be an instructive exercise ....

The first questionnaire began simply by asking the panelists' assessment of the ULI/AIA report and especially the computer forecasts. These questions were broadly open-ended, intended to generate a range of opinions as broad and unbiased as possible. For example,

1. Is the ULI/AIA Report generally consistent with the output provided by the "Control Scenario" from the model? Or are there different assumptions underlying the Report?

2. Where in Pima County do you think future growth will take place? Do you agree with the conclusions of the ULI/AIA Report on this matter? 
3. Are there important political considerations that the ULI/AIA Report overlooked?

4. Regarding the "quality of life," was the ULI/AIA Report generally accurate and sufficient? (Standard indicators of "quality of life" generally include the following....)

A second questionnaire introduced the participants to the remaining scenarios generated by the computer model and asked them, first, to evaluate the most likely and least likely of all these scenarios and to explain their choices in this regard. Second, the participants were asked to critically assess the output of all of the scenarios. Did the results seem to make intuitive sense in terms of their own experience?

With regard to some issues, the degree of initial consensus was surprising. Whether "pro-growth" or "anti-growth," for example, the panelists were in agreement that continued growth was inevitable, and a clear majority of the panelists believed that even the highest growth scenario was not unrealistic or unbelievable.

These initial questionnaires also posed a number of broadly open-ended questions concerned with the manifestations and impacts of this growth, such as:

- Where in the metropolis will this growth occur?

- Will we be able to manage this growth so as to maintain the quality of the environment?

- Will we be able to maintain Tucson's unique identity and lifestyle?

- What will be the overall impact on the quality of life?

- What are the greatest problems, or challenges, which community leaders face?

- What effect will growth have on metropolitan politics and governance?

- What will be the effects on minority groups, the poor, the aged, and other special interest groups?

These initial questionnaires served to define the range of relevant and important issues and also to stimulate thought and discussion on the many topics in question. These open-ended questionnaires also provided most of the quotes that were used in the final report and were used in turn by the media.

Based on these inital results, three more questionnaires were designed in a much more structured nature. These later questionnaires utilized increasingly specific questions in order to target the key issues that had emerged. The results of these questionnaires were used to gauge the degree of consensus, or more often the lack of consensus, among the participants. 
These questionnaires were structured in a multiple-choice format, in which participants responded to specific statements. (Participants were also encouraged throughout to add additional comments or to clarify their responses.) The range of possible responses were arrayed as follows:

1 = I completely, fully agree

$2=$ I agree

$3=$ I agree, but with reservations or hesitation

4 = No comment, no opinion, or unsure

$5=$ I disagree, but with reservations or hesitation

$6=$ I disagree

7 = I disagree completely; this is absolutely wrong

In later studies of this type, the author has slightly simplified this array, as follows:

$$
\begin{aligned}
& \text { SA }=\text { I Strongly Agree } \\
& \mathbf{A}=\text { I Agree } \\
& \mathbf{N}=\text { No opinion, No comment, or Not applicable to me } \\
& \mathbf{D}=\text { I Disagree } \\
& \text { SD }=\text { I Strongly Disagree }
\end{aligned}
$$

These questions included a wide variety of statements that asked the participants to respond with normative as well as predictive judgments. The statements were all quotes or paraphrases of responses. They were selected either to reflect commonly stated opinions or to illustrate the range of disagreement. Examples of these types of questions include the following, together with results in brackets:

\section{General Recap}

Prospects for the deterioration of air and water quality are serious enough at this point to merit a significant re-evaluation of growth and development for the area. [Strong agreement.]

Southwest Tucson will be the location of most of the low-mid priced housing in the area in the future. [Strong agreement.]

Tucson will increasingly tend to offer a job market only for the highly skilled and unskilled, with few prospects for those in between. [Mixed response.]

The tourism industry will decline in importance in the future, as Tucson grows and loses much of its original appeal. [Strong disagreement.] 
Within the next 30 years, Tucson will be seen as having a generally low quality of life, relative to other cities in the United States. [Strong disagreement.]

Previous plans for Tucson and the area have been violated in the past more than they have been realized, and there is little reason to expect any difference in the future. [Mixed response, without many strong opinions either way.]

A great deal of attention and resources should be directed into the redevelopment of the downtown. [Very strong agreement.]

\section{Alternative Scenario Number One (i.e., very high growth)}

Growth like this is not at all out of the question. [Very strong agreement.]

These additional industries would be most likely to locate in roughly the same area of Tucson as today's existing industries. [Mixed response.]

This case would result in more bitter and divided politics than today. [Mixed response, which changed to general agreement through later questionnaires; i.e., politics would become more bitter and divided no matter what happened.]

This case would drive many existing residents out of Tucson, because of increasing growth, changes, deterioration of air and water quality, traffic, etc. [Mixed response; what was eventually determined was that inmigration might slow and some residents might leave, but none of the participants had any plans to leave.]

There would be no way we could plan fast enough to keep ahead of this kind of growth. Community services would seriously deteriorate. [Mixed response; particular services were specified in later questionnaires.]

Neighboring communities such as Green Valley and Marana would benefit, on balance, from Tucson's rapid gains. [Positive response.]

Annexations would increase dramatically. [Near consensus agreement.]

Response rates tended to be somewhat higher (ranging between 25 percent and 50 percent) for the multiple-choice-style questionnaires than for the initial, more open-ended questionnaires. The final questionnaire, however, concluded with a few additional open-ended questions, and these received a good response. These questions included the following:

- Higher education-university, college, and technical school levelreceived high marks from a majority of the participants. Do you have 
any recommendations on how these schools could further increase their contribution to the community?

- A very clear majority expects serious transportation problems in Tucson within the next ten years, if not much sooner. On the other hand, there was strong dislike of expressways, as bringing to mind the unfettered growth of Los Angeles. How do you reconcile these two positions?

- A very strong majority felt that neighborhood groups are and will increasingly continue to be a major political force. In what ways?

The study resulted in a number of useful findings from the standpoint of the university (as the sponsoring agency of the study) and from the Tucson community. First, the community forum benefited simply from the identification of key, growth-related issues that emerged from the study. These served as organizing themes for the forum meeting itself, in which forum participants broke into small workshop sessions devoted to particular topics.

The results of the Delphi study were summarized with the phrase "limited consensus and persistent dissensus." Beyond the initial agreement that growth would continue, agreement was general on only a very few issues. A very clear majority, for example, believed that politics in Tucson would continue to become increasingly bitter and that the population would become more divided and increasingly concerned with self-interest. A very clear majority also forecasted an imminent transportation crisis in the city within the next five years. Both of these issues, and the few other issues that met with some consensus, proved to be very newsworthy. On many of the remaining issues that failed to meet any degree of consensus, the Delphi process was useful in clarifying the nature and degree of the differences of opinions.

Utilizing the results of the Delphi responses, the Delphi process served to complement the original data with a number of additional dimensions to or perspectives on the original forecasts. Based on the assessments of experts in particular communities or neighborhoods, for example, the Delphi study resulted in a qualitative assessment of the regional impacts of metropolitan growth, together with assessments of the impacts on minorities and other special groups. The Delphi process also provided a more qualitative differentiation among the several scenarios-how a rapid-growth scenario might differ in its impacts on the community from a moderate-growth scenario, for example.

The public response to the study was strong. Many of the study's results were cited in the local newspaper, and for several months following the study, the researchers received invitations to speak on local news shows and address local civic organizations. In every case, the researchers had the opportunity to explain the original quantitative model upon which the Delphi study was based before ex- 
panding upon the Delphi panelists' interpretations of that model-a rare level of exposure for a complex economic simulation model.

\section{An Economic Diversification Study}

In 1987, the University of Arizona's Economic Development Program was approached by representatives of an Arizona county who were concerned with the narrowness of the county's economic base. A number of mining-related industries in the county had declined severely in recent years, leaving the county highly dependent on a single, large military base. Meanwhile, the U.S. Congress at that time had begun serious debate on scaling down or even closing a number of military facilities.

The county representatives were interested in developing a plan for economic diversification in the county, possibly leading to the creation of a county-wide economic development organization. A number of the county representatives were sceptical of the need to undertake any sort of preliminary research to support such a plan. Comments included: "The last thing we need is another study-this county has already been studied to death," and "Why waste your timethis study will just gather dust on the shelf like all the others." It was clear that this study, to be approved before the fact or utilized after the fact, would have to be pragmatic in nature and would have to address aggressively these sorts of criticisms. Professionally and personally, too, the university researchers involved had no taste for undertaking such a project just to have it gather dust in the end.

The enormous diversity of the county (with individual communities' economic bases ranging from agriculture to military to tourism to retirement) suggested the complexity of any quantitative modeling effort. Many different communities, interest groups, and points of view had to be incorporated or recognized in some manner. At the same time, the research design was constrained by the county's modest resources. The Economic Development Administration of the U.S. Chamber of Commerce and the Office of Economic Adjustment of the Department of Defense provided partial research funding in order to develop a national model for this sort of problem (President's Economic Adjustment Committee 1989). Even with this support, however, the county's research resources were not adequate to support an extensive data collection and modeling approach. As a national model, too, the research design had to be realistic regarding the limited resources of the small communities and regions for which it was intended.

The project began by requesting a copy of every known planning, marketing, or economic development study that had been conducted in the county. This was done in the interest of economy and also to assail the criticism that the county had already been "studied to death." As it turned out, there were very few extant 
studies that were relevant or reasonably current. Inquiries at the state level were somewhat more successful, resulting in current industrial employment data organized by Standard Industrial Classification (S.I.C.) at the county but not community level.

The research design proposed two related studies, both of which utilized a Delphi approach. The first would be general and strategic in nature, concemed with planning, implementing, and institutionalizing economic development and diversification in the county. This part of the study is described in detail by Gibson and Miller (1990).

The second part of the study was concerned with targeting specific industries for development purposes, and it provides a better example of a Delphi process based on quantitative data. While the first part of the study utilized a large and diverse Delphi group, the second part involved a fairly small and select group of area residents who all had some experience in industrial development issues (Miller, Gibson, and Wright 1991).

For this second part of this study, a location quotient was calculated for each four-digit S.I.C. category. This location quotient compared each industrial sector's representation in the county with the representation of that industrial sector in the state as a whole. All the resulting location quotients were organized into five categories: highly overrepresented, somewhat overrepresented, average representation, somewhat underrepresented, and highly underrepresented.

The study participants were then asked to comment on each industry with which they had some knowledge or familiarity, regarding that industry's potential for development or further development in the county. The participants were asked to draw upon their knowledge of the county and their diverse areas of specialized expertise.

The instructions to the panel mentioned that if an industry is highly underrepresented in the county, in comparison with the state as a whole, that may mean that there is underrealized potential for the development of that industrial sector in the county. On the other hand, there may be very good reasons why the county is underrepresented in that industrial sector, and there may be little potential for development. The questionnaires were designed as follows:

\section{Industries with Very High Representation in the Study Area}

These are industrial sectors that, when compared to other nonmetropolitan areas of the state, have a high or very high presence in the study area. For economic development purposes, this may be interpreted in a variety of ways.... 


\begin{tabular}{|c|c|c|c|}
\hline$\underline{\text { SIC code }}$ & $\begin{array}{c}\text { Potential/ } \\
\text { priority }\end{array}$ & Emphasis & $\begin{array}{l}\text { Geographic } \\
\text { focus }\end{array}$ \\
\hline 1731 & Electrical contractors & & \\
\hline 2033 & $\begin{array}{l}\text { Fruit and vegetable } \\
\text { canneries }\end{array}$ & & \\
\hline 3679 & $\begin{array}{l}\text { Electronic components } \\
\text { manufacturers }\end{array}$ & & \\
\hline 7372 & $\begin{array}{l}\text { Management, consulting, } \\
\text { and PR services }\end{array}$ & & \\
\hline
\end{tabular}

The participants were instructed to comment in at least three categories for each industrial sector with which they were familiar. First, they were asked to comment on the potential and priority for each industrial sector, as follows:

\section{Code Description}

3 Excellent potential for further development/top priority

2 Good potential-intervention recommended if program resources are available

1 Some potential, however no intervention is called for-let the "market" take its course

$0 \quad$ No opportunity for development

Second, the participants were asked to comment on the recommended development emphasis, or approach, for each industrial sector as follows:

\section{Code Description}

a Emphasize the attraction of firms from outside the study area

b Emphasize retaining and expanding existing local firms

c Emphasize the development of new "homegrown" firms

Finally, the participants also were asked to attempt to "regionalize" the data. That is, which individual communities hold the greatest promise for the development of particular industries? For this purpose, the participants were provided with a list of abbreviations corresponding to communities in the county.

The entire process only involved two "rounds," since there was a high degree of agreement among the participants from the first questionnaire. Naturally, participants also disagreed on many issues. The process yielded enough of a consen- 
sus, though, to provide the county with broad and specific directions for future development action.

\section{CONCLUSIONS}

In the case of the Tucson metropolitan growth study, the Delphi component complemented the quantitative analysis in a number of ways that were important, appropriate, and useful for policy and planning purposes. Not only did the Delphi study serve to publicize the original quantitative model, it encouraged dozens of the community's opinion leaders to analyze, conceptualize, and challenge the model, its input, and its output. The Delphi process, and the resulting community forum, facilitated a community dialogue on the model's forecasts that might not have been achieved in any other way.

In the case of the county industrial targeting model, the Delphi methodology served to guide the decision-making process of local developers in at least two ways. First, the Delphi method encouraged local developers to make use of available quantitative data and modeling to the fullest extent possible. The design of the Delphi method also cautioned developers against "overinterpreting" these available data. That is, the instructions explained as clearly as possible the point at which further interpretation would depend upon intuition and informed judgment rather than hard data.

In both of these cases, the use of the Delphi method may have helped encourage decision makers to implement plans and policies based on the results of these studies. It is reasonable to assume that policymakers will be more likely to implement a study that they fully understand and in which they have confidence. In the case of the industrial targeting study, those who commissioned, participated in, and would (or would not) utilize the research were clearly satisfied with its comprehensiveness, relevance, and usefulness. This level of satisfaction was particularly significant, given the original criticism and skepticism of "just another study."

Perhaps even more importantly, a Delphi process, such as described here, can serve an implicit, longer-term purpose: that of an educational experience for policymakers, policy shapers, and other potential consumers of regional data and analysis. Used in the manner described here, the Delphi method provides one way to help accustom these people to incorporating regional data and analysis appropriately into their decision-making process, as opposed to overlooking the available data, basing a decision on anecdotal information, or simply giving lip service to the use of analysis. On the other hand, this type of Delphi method can also provide some instruction in the cautious and critical use of regional data. 
Both of these educational objectives serve the purpose of a concerned regional scientist: providing good information as a sound foundation for planning and policy decisions.

\section{REFERENCES}

Bachelor, Lynn W. "Michigan, Mazda, and the Factory of the Future: Evaluating Economic Development Incentives." Economic Development Quarterly 5 (1991): 114-25.

Bardecki, Michal J. Wetland Conservation Policies in Southern Ontario: A Delphi Approach. Downsview, Ontario: geographical monographs, Department of Geography, Atkinson College, 1984.

Benarie, M. "Delphi and Delphi-Like Approaches with Special Regard to Environmental Standard Setting." Technological Forecasting and Social Change 33 (1988): 149-58.

Cavallisforza, V., and L. Ortolano. "Delphi Forecasts of Land-Use-Transportation Interactions." Journal of Transportation Engineering 110 (1984): 324-39.

Chamey, Alberta H., and Arthur L. Silvers. "Tucson Development: Five Simulations for Prospects and Problems." In Development for Tomorrow: Options and Choices. Tucson: University of Arizona, 1985.

Cicarelli, J. "The Future Economics: A Delphi Study." Technological Forecasting and Social Change 25 (1984): 139-57.

Cundiff, W. E. "Interactive Software for the Capture, Management, and Analysis of Data in Delphi." Technological Forecasting and Social Change 28 (1985): 173-85.

Dalkey, N., and O. Helmer. "An Experimental Application of the Delphi Method to the Use of Experts." Management Science 9 (1963): 458.

Delbecq, André L., Andrew Van de Ven, and David H. Gustafson. Group Techniques for Program Planning: A Guide to Nominal Group and Delphi Processes. Glenview, Ill.: Scott, Foresman, 1975.

DeSario, Jack, and Stuart Langton. Citizen Participation in Public Decision Making. New York: Greenwood Press, 1987.

Erffmeyer, R. C., et al. "The Delphi Technique: An Empirical Evaluation of the Optimal Number of Rounds." Group and Organization Studies 11 (1986): 120-8.

Gibson, Lay James, and Mark M. Miller. "A Delphi Model for Planning 'Preemptive' Regional Economic Diversification." Economic Development Review 8, no. 2 (1990): 34-41. 
Gibson, Lay James, Mark M. Miller, Sally A. Rusden, and N. Gene Wright. Preemptive Economic Development in Cochise County, Arizona: A Model Economic Diversification Planning Process for an Area with a High Concentration of Military Employment. Tucson: Economic Development Program, University of Arizona, 1989a.

- Preemptive Economic Development: A Model Economic Diversification Planning Process for Areas with High Concentrations of Military Employment. Tucson: Economic Development Program, University of Arizona, 1989b.

Gordon, T. J., and O. Helmer. Report on a Long-Range Forecasting Study. The Rand Corporation, Paper no. 2-2982, 1964.

Heikkila, Eric, and Peter Leckie. "Expert Evaluation of Municipal Revenues and Expenditures by Land Use Category." Journal of Planning Education and Research 8 (1989): 35-44.

Hitch, P. J. "Professional Communications in Cancer Care: A Delphi Survey of Hospital Nurses." Journal of Advanced Nursing 8 (1983): 413-22.

Kruus, P. "Utilization of Delphi Methods for University Planning." Technological Forecasting and Social Change 24 (1983): 269-75.

Ley, G. F., and G. Anderson. "The Delphi Technique in Urban Forecasting." Regional Studies 9 (1975): 243-9.

Linstone, Harold A., and Murray Turoff. The Delphi Method: Techniques and Applications. Reading, Mass.: Addison-Wesley Publishing Company, 1975.

Mann, Lawrence D., and Mark M. Miller A More Complete Vision of Tucson's Future: The "Quality- Development" Delphi Panel Study. Report prepared for the University of Arizona-sponsored community forum: Development for Tomorrow: Options and Choices, 1985.

Masser, Ian, and Paul Foley. "Delphi Revisited: Expert Opinion in Urban Analysis." Urban Studies 24 (1987): 217-25.

Miller, A. "The Delphi Approach to the Mediation of Environmental Disputes." Environmental Management 10 (1986): 321-30.

Miller, Mark M., Lay James Gibson, and N. Gene Wright. "Location Quotient Analysis: A Basic Tool for Economic Development Analysis." Economic Development Review 9, no. 2 (1991): 65-68.

Murray, J. J., L. L. Pipino, and J. P. Vangigch. "A Pilot Study of Fuzzy Set Modification of Delphi." Human Systems Management 5 (1985): 76-80.

Nelms, K. R., and A. L. Porter. "EFTE: An Interactive Delphi Method." Technological Forecasting and Social Change 28 (1985): 43-61.

Ozbekhan, Hasan. "The Future of Paris: A Systems Study in Strategic Urban Planning." In Management Handbook for Public Administrators, edited by John W. Sutherland. New York: Van Nostrand Reinhold, 1978. 
Patton, Michael Quinn. Qualitative Evaluation and Research Methods. 2d ed. Newbury Park, Calif.: Sage, 1990.

Pelton, J. N. "The Future of Telecommunications: A Delphi Survey." Journal of Communication 31 (1981): 177-89.

Preble, John F. "Public Sector Use of the Delphi Technique." Technological Forecasting and Social Change 23 (1983): 75-88.

President's Economic Adjustment Committee, Office of Economic Adjustment, Office of the Assistant Secretary of Defense (Force Management and Personnel). Diversifying Defense Dependent Communities, Community Guidance Manual XI. Washington, D.C.: The Pentagon, 1989.

Riggs, Walter E. "The Delphi Technique: An Experimental Evaluation." Technological Forecasting and Social Change 23 (1983): 89-94.

Sackman, H. Delphi Critique, Expert Opinion, Forecasting and the Group Process. Lexington, Mass.: Lexington, 1975.

Scott, George M., and Pontus Troberg. Eighty-eight International Accounting Problems in Rank Order of Importance: A Delphi Evaluation. Sarasota, Fla.: American Accounting Association, 1980.

Setty, K. P. S., S. Padmanab, and R. Nataraja. "A National Energy Conservation Policy Delphi: Report of the Findings." Technological Forecasting and Social Change 31 (1987): 257-67.

Shands, F., and R. R. Levary. "Weighting the Importance of Various Teacher Behaviors by the Use of the Delphi Method." Education 106 (1986): 306-20. Shelton, J. R. "A Delphi Study to Identify Future Roles for Physicians Assistants." Journal of Medical Education 59 (1985): 962-3.

Side, J. "Delphi-2000: Forecasting Environmental Issues and Controls." Marine Pollution Bulletin 17 (1986): 487-8.

Strauss, Harlan J., and L. Harmon Zeigler. "The Delphi Technique and Its Uses in Social Science Research." In Reaching Decisions in Public Policy and Administration, edited by Richard D. Bingham and Marcus E. Ethridge. New York: Longman, 1982.

Sviden, O. "Future Information Systems for Road Transport: A Delphi Panel-Derived Scenario." Technological Forecasting and Social Change 33 (1988): 159-78.

Weaver, M. "Using Delphi for Curriculum Development." Training and Development Journal 42 (1988): 18-20.

Winter, G., and K. Gunjal. "Computerized Delphi: An Application to Quota Value Determination in the Quebec Dairy Industry." Canadian Journal of Agricultural Economics 34 (1986): 417-31. 